\title{
Enhancement of Workability of Cement-Poor Concrete by Optimizing Paste Content
}

\author{
Mohammed Hatem Mohammed ${ }^{1,2 *}$, Nadhir Al-Ansari' ${ }^{1}$, Sven Knutsson ${ }^{1}$ \\ ${ }^{1}$ Deparment of Civil, Environmental and Natural Resources Engineering, Luleå University of Technology, Luleå, \\ Sweden \\ ${ }^{2}$ Department of Civil Engineering, University of Mosul, Mosul, Iraq \\ Email: ${ }^{\text {mohammed.hatem@ltu.se }}$
}

Received 10 September 2014; revised 31 October 2014; accepted 12 November 2014

Copyright (C) 2014 by authors and Scientific Research Publishing Inc.

This work is licensed under the Creative Commons Attribution International License (CC BY). http://creativecommons.org/licenses/by/4.0/

(c) (i) Open Access

\section{Abstract}

This study describes the performance of concrete in fresh state, intended for sealing deep boreholes in the host rock of radioactive repositories. Set of different paste volumes, combinations of water-to-powder ratios and fine aggregate contents have been performed within the frame of this study. The main objective was to search for tendencies, logical connections and phenomena that occur for different combination of materials regarding the fluidity and segregation and mainly the effect from the (paste) or fine aggregate content. It shall be pointed out that this investigation is a suggestion on how concrete can be optimized using two simple test methods based on changing the paste content. The results highlighted the importance of having sufficient amounts of filler and cement paste for separate and carry larger particles, which gives the concrete good workability and fluidity at casting. It was concluded that the slump behaviors can be optimized based on the adjustments of the superplastisizer dosage.

\section{Keywords}

Concrete, Paste Content, Workability, Talc, Void Volume

\section{Introduction}

Deep boreholes made for site investigation of repositories for high-level radioactive waste (HLW) and for disposal of such waste are proposed to be sealed by a series of concrete and clay plugs for preventing released ra-

\footnotetext{
${ }^{*}$ Corresponding author.
} 
dionuclides to reach the biosphere. Following a proposed principle for sealing of long boreholes in a rock mass hosting a repository for HLW, those parts of the holes where the rock has few fractures and low hydraulic conductivity are sealed with clay whereas those intersecting permeable fracture zones only require physically stable filling in the form of cement-poor concrete [1].

The concrete seals to be cast in boreholes should have a minimum amount of cement for minimizing the mutual chemical impact on the contacting clay seals [2]. This can be achieved by keeping the cement/aggregate ratio very low, using aggregate material with high internal friction after maturation, and also by using low-pH cement [3]. The bearing capacity of the concrete must be sufficiently high in order to carry the clay seals, which consist of perforated tubes filled with compacted smectite-rich clay. For avoiding creation of organic colloids from organic superplastisizers that can serve as catchers and carriers of radionuclides from a repository, inorganic substances and talc should be used. Consequently, a hydrophobic easy-slipping mineral, was taken as a candidate material. In addition, this mineral would interact with the cement component and produce strengthening reaction products. The desire to give the concrete a high internal friction after maturation led to the decision to use freshly crushed quartzite as main aggregate component. For achieving a suitable grain size composition, finer material should be added and in this case it was fine quartz-rich sand [4]-[6]. The major aims of this pilot study were: 1) To check the tendencies, logical connections and phenomena that occur for different combination of materials regarding the fluidity and mainly the effect from changing the paste content; 2) To see practically the performance of talc as superplastisizer in freshly prepared concrete.

\section{Experiments}

\subsection{Materials}

Merit 5000 cement delivered by the SSAB Merox AB, Oxelösund was used. Table 1 shows the characteristics of this cement.

The need for chemical integrity led to the choice of quartz as the major aggregate component, whereas two different sizes were used. A coarse fraction consisted of crushed quartzite of $2700 \mathrm{~kg} / \mathrm{m}^{3}$ specific density, and quartz powder as a minor aggregate component. This powder, termed Norquartz 45, was delivered by the Sibelco Nordic, Lillesand, Norway. The specific density, granulometry and chemical compositions of Norquartz 45 are shown in Table 2 [3].

Table 1. Merit 5000 cement characteristics.

\begin{tabular}{|c|c|c|c|}
\hline \multicolumn{2}{|c|}{ Analysis } & Unit & SS-EN 196-1, 2 and 3 \\
\hline \multicolumn{2}{|c|}{$\mathrm{MgO}$} & $\%$ & 16.6 \\
\hline \multicolumn{2}{|c|}{ LOI } & $\%$ & -1.23 \\
\hline \multicolumn{2}{|c|}{ LOI compensated for $\mathrm{S}^{2-}$ oxidation } & $\%$ & 1.43 \\
\hline \multicolumn{2}{|c|}{$\mathrm{SO}_{3}$} & $\%$ & 0.085 \\
\hline \multicolumn{2}{|c|}{ Sulfide } & $\%$ & 1.33 \\
\hline \multicolumn{2}{|c|}{$\mathrm{Cl}^{-}$} & $\%$ & $<0.01$ \\
\hline \multicolumn{2}{|c|}{ Glass content } & $\%$ & 99 \\
\hline \multicolumn{2}{|c|}{ Density } & $\mathrm{g} / \mathrm{cm}^{3}$ & 2.9 \\
\hline \multicolumn{2}{|c|}{ Specific surface area } & $\mathrm{m}^{2} / \mathrm{kg}$ & 470 \\
\hline \multicolumn{2}{|c|}{ Moisture content } & $\%$ & 0.09 \\
\hline \multirow{2}{*}{ Initial setting } & Water content & $\%$ & 27.0 \\
\hline & Setting time & $\min$ & 210 \\
\hline \multirow{2}{*}{ Compressive strength } & 7 days & MPa & 23.3 \\
\hline & 28 days & $\mathrm{MPa}$ & 50.4 \\
\hline
\end{tabular}


Table 2. Properties of fine aggregate “Norquartz 45” [3].

\begin{tabular}{cc}
\hline & Particle size distribution \\
\hline Size $(\mu \mathrm{m})$ & Percent finer \\
$<10$ & 38 \\
$<20$ & 68 \\
45 & 99.2 \\
$\mathrm{Component}$ & Average (\%) \\
$\mathrm{SiO}_{2}$ & 99.6 \\
$\mathrm{Al}_{2} \mathrm{O}_{3}$ & 0.25 \\
$\mathrm{Fe}_{2} \mathrm{O}_{3}$ & 0.02 \\
$\mathrm{LOI}$ & 0.15 \\
Density $\left(\mathrm{g} / \mathrm{cm}^{3}\right)$ & 2.65 \\
$\mathrm{pH}$ & 6.5 \\
\hline
\end{tabular}

Finely milled substance called "talc" manufactured by VWR International Company UK, which was used as superplastisizer and conditioner. Its chemical composition is $3 \mathrm{MgO} \cdot 4 \mathrm{SiO}_{2} \cdot \mathrm{H}_{2} \mathrm{O}$ and is hydrophobic and serves as lubricator. Its grain size analysis is shown in Figure 1.

\subsection{Batch Preparation}

A Hobart type mixer was used to prepare all the mixes (Figure 2). All dry materials (cement, talc, fine and the coarse aggregates) were mixed for one minute. Then, the water was added and the whole mixture was mixed for another 5 minutes.

\subsection{Hypothesis and Methodology}

\subsubsection{Cement Paste Content Based Composition of Concrete}

Literature studies and tests have given results indicating that there are several parameters that influence the properties of fresh concrete. One of them is the paste: cement and water work together as a grease in the fresh concrete. Consequently, it is important to know the effect and hence the dosage of the paste that might be of interest, which is usually decided by experience. The common principle is to balance the amounts of constituents so as to have the voids in the aggregate mixture filled by paste [7] [8]. The present work started by the local packing degree as a starting point, then the amount of cement paste was determined. The idea is to completely fill the voids that are created by the aggregates.

The packing degree for a certain aggregate (70\% coarse and $30 \%$ fine) is found to be $(0.670)$. The remaining volume is hence $33 \%$ of the total volume. Applying these ratios to a system having 1 liter volume, the aggregate will represent $0.67 \mathrm{~L}$ and the voids $0.33 \mathrm{~L}$, which will be filled with paste.

The grain size distribution of the aggregate mixture of 70\% "coarse" and 30\% "fine" quartzite, was noticed to be more suitable and Fuller than the "50/50\%" mixture (cf. Figure 3). For this reason this ratio was used in all the experiments. The paste adopted in this study consists of water, cement and talc. The densities are known, the mass of each part can be calculated and the fresh concrete is thereafter mixed together.

\subsubsection{Mix Proportions}

Concrete mix volume adopted was one liter, consisting of aggregate and paste. In order to obtain valuable and informative results, five paste volumes were assumed: the one needed to fill the voids exactly, i.e. (original paste volume) and the others were changed by increasing the paste volume by $0.07 \mathrm{~L}$ after starting point with $0.13 \mathrm{~L}$, thereby creating five systems. The first, second and so on were filled $100 \%, 113 \%, 120 \%, 127 \%$ and $134 \%$ of the paste volume respectively. Table 3 demonstrates the mix calculations of the recipes based on the local 


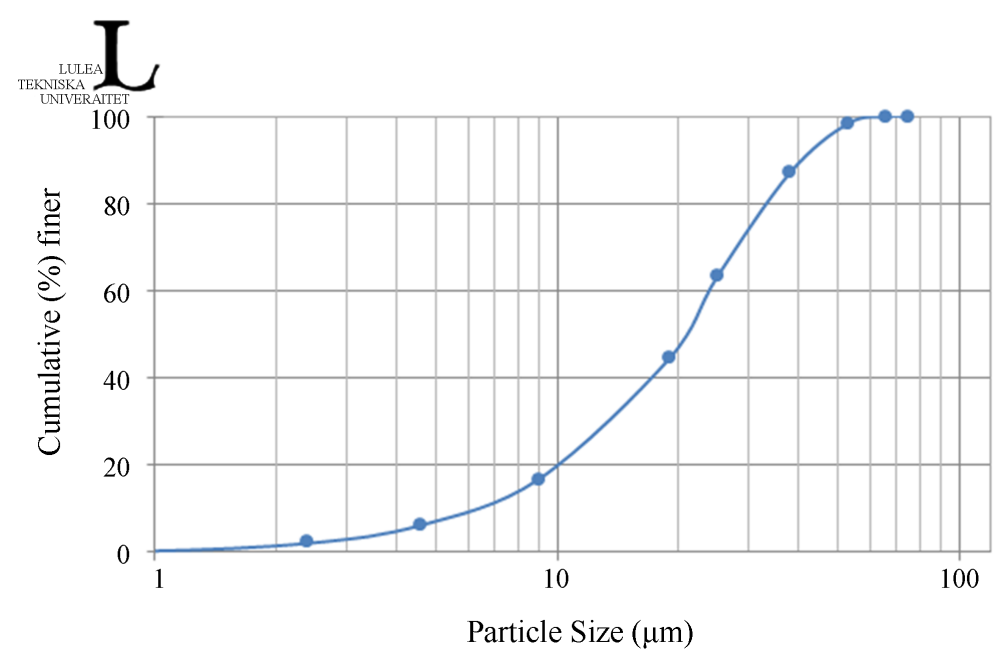

Figure 1. Grain size analysis of talc.
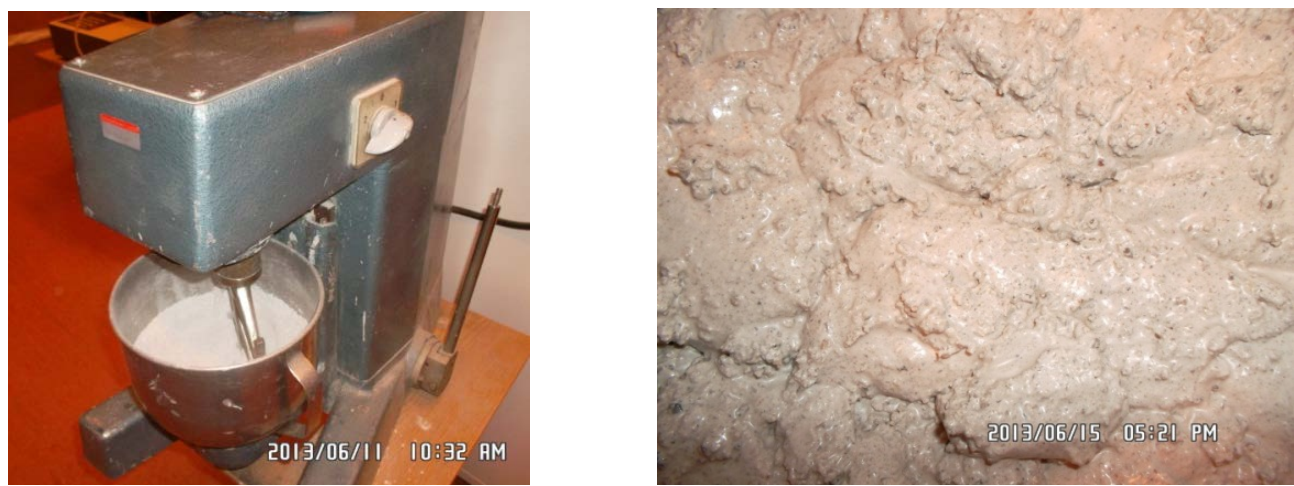

Figure 2. Concrete mixture preparation with the degree of fluidity being illustrated by the right photo.

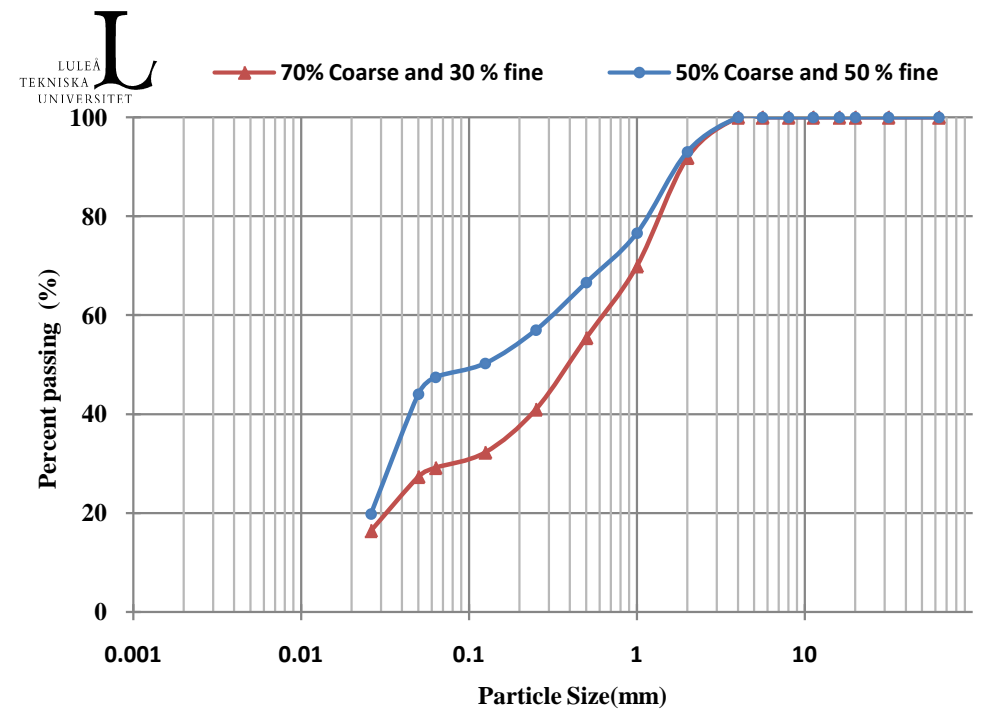

Figure 3. Grain size analysis of aggregate mixture.

packing degrees. The unit weight of various concrete recipes were determined from the laboratory tests and ranged between $2050-2100 \mathrm{~kg} / \mathrm{m}^{3}$. 
Table 3. Concrete mix components (\% of total mixture).

\begin{tabular}{ccccccc}
\hline Concrete mix recipe & $\# 1$ & $\# 2$ & $\# 3$ & $\# 4$ & $\# 5$ \\
\hline Merit 5000 cement & 3.2 & 4.3 & 4.8 & 5.3 & 5.8 & 8.2 \\
Talc & 4.5 & 6.1 & 6.9 & 17.4 & 19.2 & 20.8 \\
Water & 11.4 & 15.5 & 21.3 & 20.4 & 19.6 & 45.6 \\
Fine aggregate & 24.3 & 22.2 & 49.6 & 47.5 & 0.237 & 0.262 \\
Coarse aggregate & 56.6 & 51.9 & 0.210 & 0.27 & 0.34 \\
Water to powder ratio & 0.128 & 0.183 & 0.13 & 0.20 & 0.27 \\
Excess paste added (L) & 0.00 &
\end{tabular}

\subsubsection{Mini-Slump Cone Test}

The purpose of the mini slump cone test is basically the same as the standard slump cone test for checking the workability of the concrete candidates. The only difference was the size of the cone and the particles of the tested material. Here, the test was based on the same principles as the ordinary slump test concrete. The sample was filled up in a slump cone; excessive material was stroked out and then lifted in a slow vertical movement. Then the height of the peak of the slumped concrete was measured keeping in mind that large outflow means high fluidity [4] [7].

\section{Results}

\subsection{Workability}

To investigate the function of the cement paste, and the role of talc as a superplastisizer and conditioner, slump test was performed. Normally, a high value of the slump is required. However, this does not mean that the fresh properties of the concrete are satisfactory. The visual information regarding the concrete's aspects should be noted also during the test. Slump test results alone are not enough to give an indication about properties such as consistency, stickiness and separation. Therefore, photos were captured for all tests. Five general behaviors were recognized (Figure 4).

Based on the observation of the mixes behaviors, such properties as consistency, stickiness and separation tendency has been indicated and described below in Table 4.

Based on the former observations, three zones were defined as follow:

1. Unsaturated zone: When the voids between the aggregate were totally filled with paste and also with a little more extra paste, but not enough to be as lubricant, carrier and cover for these particles. In this zone, paste volume ratio started at voids filled exactly, i.e. $100 \%$ until just before $20 \%$ more extra volume.

2. Saturated zone: In this zone the paste volume start to cover all particles and also to carry them, improvements were clearer in the mixes. Here, the workability started to be improved after increasing the paste volume $20 \%$ and more up to just before $34 \%$.

3. Segregation zone: By adding more paste, the particle system was "overfilled", float and had a stony appearance. After 34\% extra paste volume, tendency to separation slightly started to be cleared.

These zones had also been specified in Figure 5. In this figure also, the mini slump results plotted against the superplastisizer ratios. It can be concluded that talc serves to reduce the viscosity in the preparation stage, and relatively high fluidity can be achieved with adjustments of the superplastisizer.

\subsection{Segregation}

Resistance to segregation is essential and it is one of the criteria for this type and use of concrete which shall always keeps its homogeneity. After slumping test, it is possible by visual inspection basis, to decide if a mix of concrete is segregated or not by performing the "scrap test" [9]. The cone of concrete after the test does not tell anything about segregation, but when the sample is scrapped off the testing plate with a trowel it will be very obvious whether this sample is segregated or not (Figure 6). 


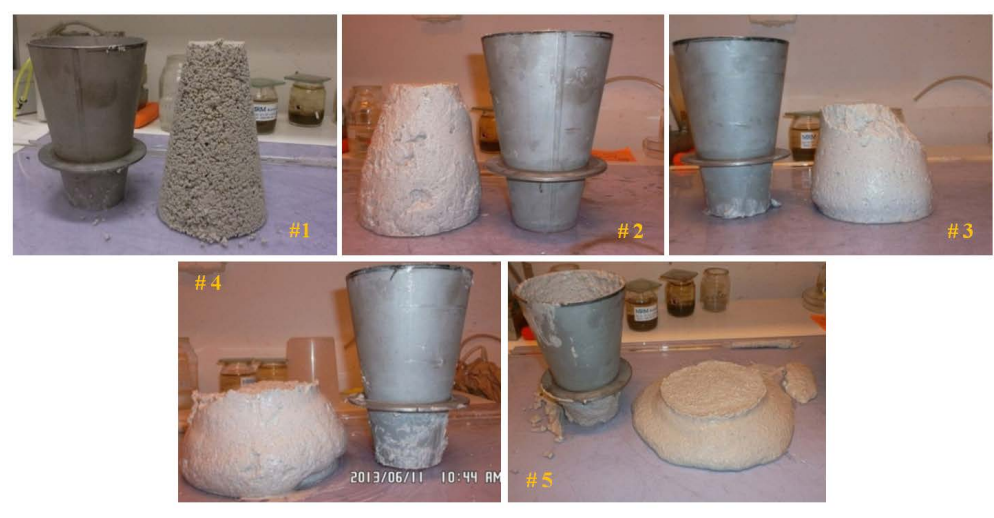

Figure 4. Slumping behaviors of concrete.

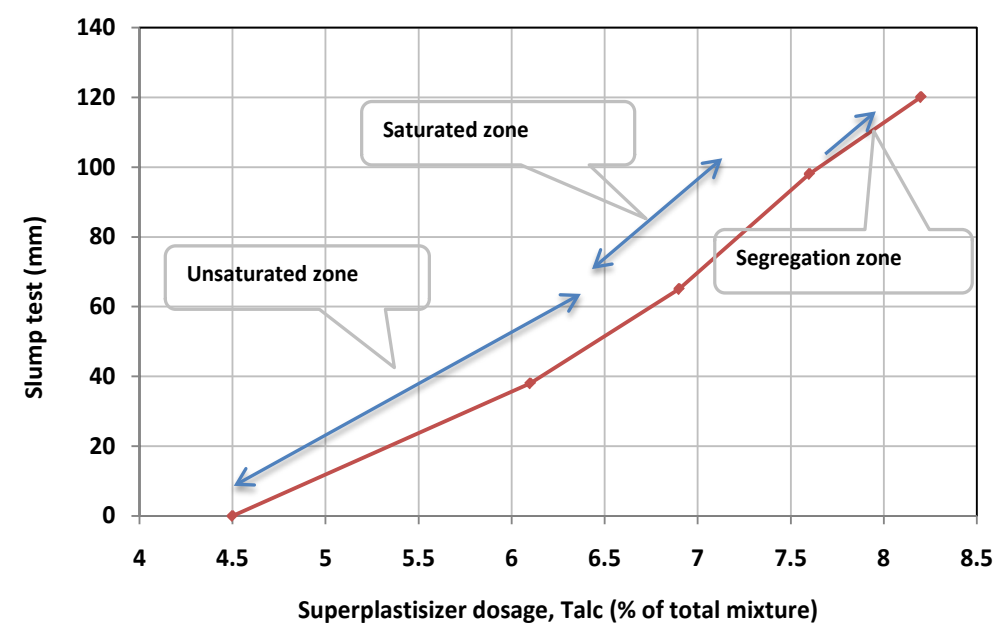

Figure 5. Slump test plotted versus the different ratios of superplastisizer, $4.5 \%, 6.1 \%, 6.9 \%, 7.6 \%$ and $8.2 \%$.

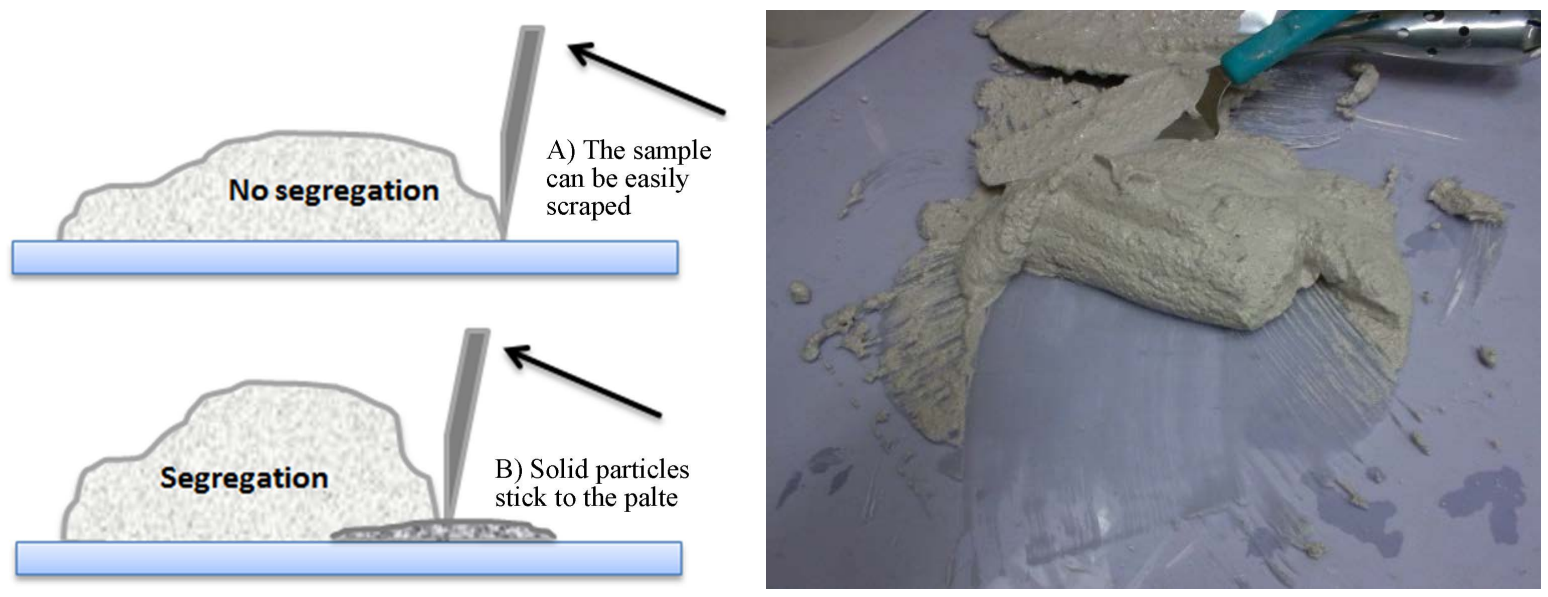

Figure 6. A "scrap test" showing cement-poor concrete mix homogeneity. Left: How this test can be done by the trowel; Right: A real case for the mix recipe \#4.

In some cases, the segregation can be interpreted by the relationship between the mini slump results and the dosage of superplastisizer (cf. Figure 5). See the slight bend before the segregation zone. Generally, this relation is a straight line all the way up to segregation [9]. 


\subsection{The Effects of Constitutes}

The "excess paste theory" was introduced by Kennedy [10], when he formulated the influence of the fine aggregate content on the workability of fresh concrete [9]. For workable concrete, the paste content must be less than or equal to the void volume in the dry aggregate skeleton [10]. Then, the workability will be improved for any degree of excess of cement paste. The amount of excess of cement paste, however, depends on, cement paste consistency and aggregates surface area where with larger surface area; greater excess paste volume is required [10].

In Figure 7, the mini slump results are plotted against the corresponding fine aggregate content (the red one) for all mixes. It can be seen that slump results increased with the decrease of fine aggregate contents. The slump results, however can be always adjusted and increased by increasing the excess paste volume and hence the superplastisizer. The favorite workability is normally required to keep it in the saturation zone (cf. Figure 5), and then the distance to the separation point will be increased [9].

The results of mini slump results plotted against water content (the blue curve) in Figure 7. It can be noticed that the favorable workability of the concrete based on the paste volume correspond to the behavior in the saturated zone, as pointed out in Figure 7.

\section{Conclusions}

Concretes with crushed quartzite as coarse aggregate, quartz powder as fine aggregate, and with talc as superplasticizer were prepared and investigated for possible use in sealing deep boreholes. This concrete was poor in cement content, where its percentage was 3 - 6 by weight for all mixes. Major conclusions that were extracted from this work are as follow:

\section{Table 4. Description based on observation of slumping behaviors of concrete mixes.}

\begin{tabular}{|c|c|c|c|}
\hline Mix & Voids filled ratio (\%) & Slump (mm) & Description \\
\hline \#1 & 100 & 0 & The concrete has no slump and the shape is basically similar to the slump cone. \\
\hline \#2 & 113 & 38 & The mix has poor slump, suspected porosity and rigid appearance. \\
\hline \#3 & 120 & 65 & $\begin{array}{c}\text { The mix has become more conditioned, still suspected porosity and the consistency } \\
\text { was stickier. }\end{array}$ \\
\hline \#4 & 127 & 98 & $\begin{array}{l}\text { The mix was more lean and smooth. Also, the concrete doesn't float, and has a good } \\
\text { consistency. }\end{array}$ \\
\hline \#5 & 134 & 120 & $\begin{array}{l}\text { Top edge from cone is still accentuated while the lower part of the shape started to } \\
\text { move. The concrete does look float and a slight tendency for separation. }\end{array}$ \\
\hline
\end{tabular}

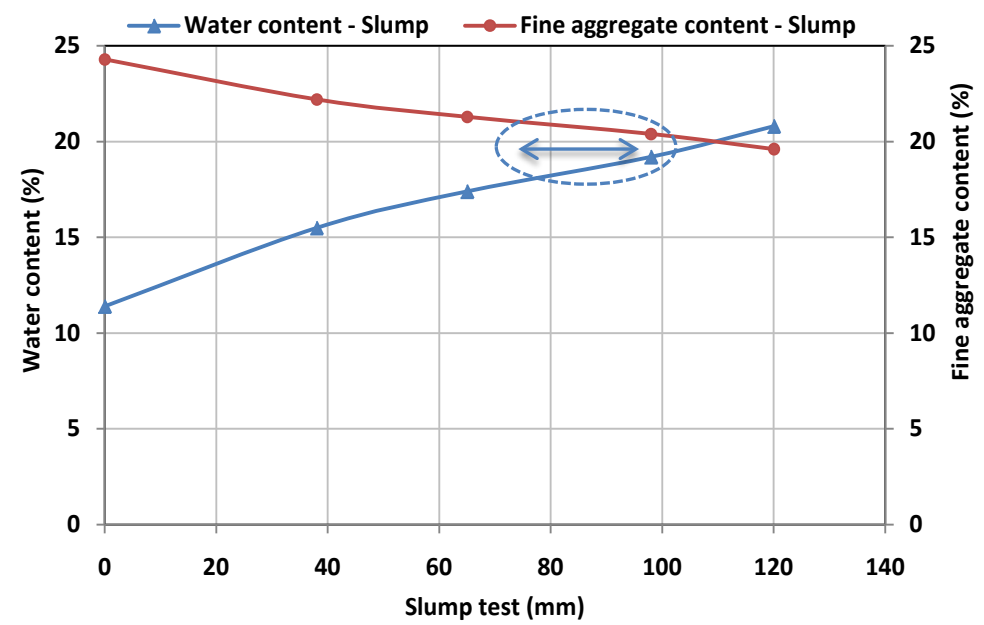

Figure 7. The sensitivity against the variations of fine aggregate and water contents behavior in slump test results. 
Fine aggregate content controls most of the properties of the concrete for getting the aggregate skeleton as dense as possible. On the other hand, the results highlighted the importance of having sufficient amounts of filler material and cement paste to separate and carry larger particles. Hence, giving the concrete good workability and fluidity at casting, aggregate voids should be slightly "overfilled" with about $20 \%$ - 34\% extra paste volume. The results also highlighted the role of talc as mineral component which served as an alternative superplastisizer and as conditioner of the concrete. Finally, the concrete with optimal aggregate distribution, minimum voids and sufficient content of paste can be optimized based on simple and quick test methods.

\section{Acknowledgements}

The laboratory tests were performed at Luleå University of Technology's Complab, and the authors would like to give their appreciation to them. The authors gratefully acknowledge the Sibelco Nordic, Lillesand, Norway, for providing Norquartz 45 which has been used as fine aggregate through the present study.

\section{References}

[1] Pusch, R., Ramqvist, G., Bockgård, N. and Ekman, L. (2011) Sealing of Investigation Boreholes, Phase 4. Final Report SKB, Swedish Nuclear Fuel and Waste Management Co., Stockholm.

[2] Pusch, R., Warr, L., Grathoff, G., Pourbakhtiar, A., Knutsson, S. and Ramqvist, G. (2013) A Study on Cement-Poor Concrete with Talc for Borehole Sealing in Rock Hosting Radioactive Waste. Comunicações Geológicas, 5, 251-267.

[3] Mohammed, M.H., Pusch, R., Al-Ansari, N., Knutsson, S., Jonasson, J.-E., Emborg, M. and Pourbakhtiar, A. (2013) Proportioning of Cement-Based Grout for Sealing Fractured Rock-Use of Packing Models. Engineering, 5, 765-774. http://dx.doi.org/10.4236/eng.2013.510092

[4] Pourbakhtiar, A. (2012) Pilot Study of Method for Constructing Concrete Seals and Fracture Grouts in Deep Boreholes and Cementitious Backfills in Tunnels, Drifts and Shafts in Crystalline Rock. M.Sc. Thesis, Luleå University of Technology, Luleå.

[5] Mohammed, M.H., Pusch, R., Al-Ansari, N., Knutsson, S., Emborg, M., Nilsson, M. and Pourbakhtiar, A. (2013) TalcBased Concrete for Sealing Borehole Optimized by Using Particle Packing Theory. Journal of Civil Engineering and Architecture, 7, 440-455.

[6] Pusch, R., Warr, L., Grathoff, G., Pourbakhtiar, A., Knutsson, S. and Mohammed, M.H. (2013) A Talc-Based CementPoor Concrete for Sealing Boreholes in Rock. Engineering, 5, 251-267. http://dx.doi.org/10.4236/eng.2013.53036

[7] Kristoffer, N. (2005) Packing Theory for Crushed Aggregates in Concrete. Master Thesis, ETSEIB, Betongindustri AB, Luleå University of Technology, Luleå.

[8] Mohammed, M.H., Pusch, R., Al-Ansari, N. and Knutsson S. (2012) Optimization of Concrete by Minimizing Void Volume in Aggregate Mixture System. Journal of Advanced Science and Engineering Research, 2, 208-222.

[9] Utsi, S. (2008) Performance Based Concrete Mix-Design Aggregate and Micro Mortar Optimization Applied on SelfCompacting Concrete Containing Fly Ash. Ph.D. Thesis, Luleå University of Technology, Luleå.

[10] Kennedy, C.T. (1940) The Design of Concrete Mixes. Proceedings of the American Concrete Institute, 36, 373-400. 
Scientific Research Publishing (SCIRP) is one of the largest Open Access journal publishers. It is currently publishing more than 200 open access, online, peer-reviewed journals covering a wide range of academic disciplines. SCIRP serves the worldwide academic communities and contributes to the progress and application of science with its publication.

Other selected journals from SCIRP are listed as below. Submit your manuscript to us via either submit@scirp.org or Online Submission Portal.
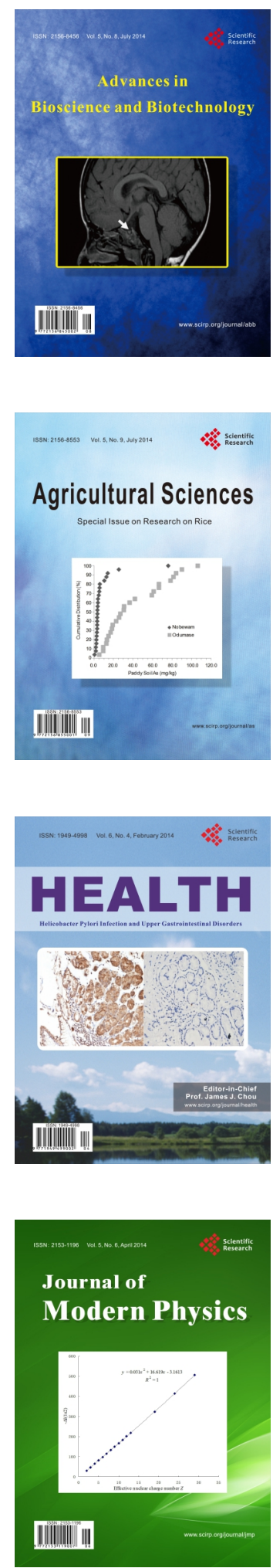
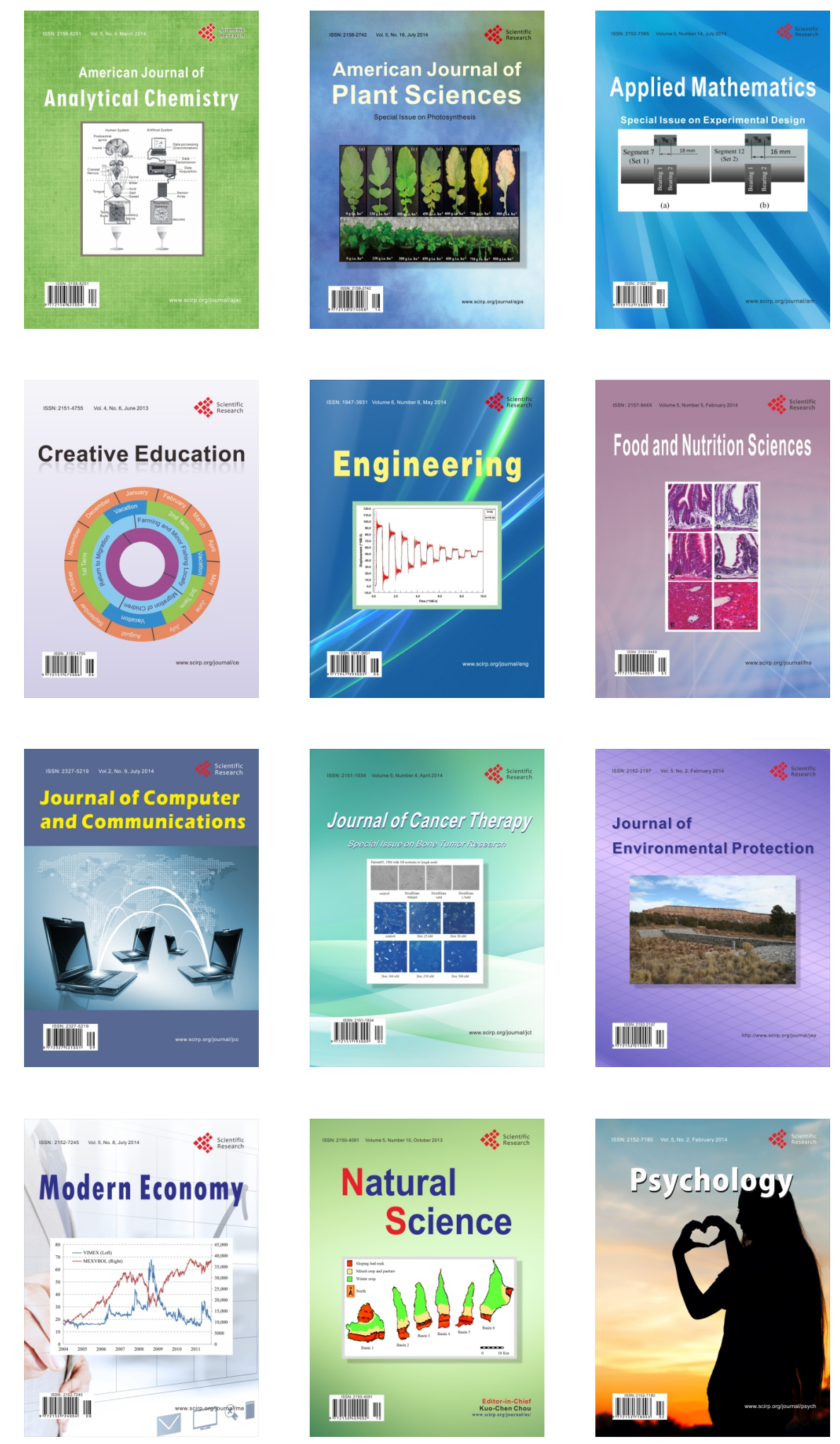